\title{
Tissue Oxygenation and Muscular Substrate Turnover in Two Subjects with High Hemoglobin Oxygen Affinity
}

\author{
Bengt Wranne, Gösta Berlin, Lennart Jorfeldt, and Niels Lund, \\ Departments of Clinical Physiology and of Internal Medicine and \\ Anesthesiology, University Hospital, S-581 85 Linköping, Sweden
}

A B S T R A C T Oxygen transport to and substrate turnover in leg muscle were studied at rest and during light and heavy upright bicycle exercise in two brothers with a hereditary hemoglobinopathy associated with high oxygen affinity $\left(P_{50}=13 \mathrm{mmHg}\right)$. Femoral venous oxygen tension was below normal and femoral venous oxygen saturation above normal at rest and during exercise. Thus, the arterial-femoral venous oxygen saturation difference was decreased. Despite a compensatory increase in hemoglobin concentration, the arterial-femoral venous oxygen content difference tended to be below normal at heavy exercise. Approximately $25 \%$ of the oxygen was delivered via the abnormal hemoglobin at relative heavy exercise. Arterial lactate levels, lactate release, and muscle lactate concentration were not increased at any level of exercise. Glucose, alanine, pyruvate, and glycerol turnover were essentially normal, but the glycogen and creatine phosphate stores were abnormally depleted at the termination of heavy exercise. The exercise electrocardiogram (ECG) was normal, indicating that myocardial oxygenation was adequate. Muscle-surface oxygen pressure fields were normal at rest (not investigated during exercise). It is concluded that the high oxygen affinity of the hemoglobin in our two subjects did not lead to heart or skeletal muscle hypoxia during heavy exercise, as judged from the ECG and from the leg lactate turnover. Despite the lack of evidence for muscle hypoxia, the subjects experienced leg muscle fatigue and the creatine phosphate and glycogen stores were depleted more than normally.

\section{INTRODUCTION}

A decrease in hemoglobin-oxygen affinity (a right-shift of the oxygen dissociation curve (ODC) ${ }^{1}$ has been con-

Received for publication 16 July 1982 and in revised form 22 June 1983.

${ }^{1}$ Abbreviations used in this paper: a, arterial; ACD, acid citrate dextrose; CP, creatine phosphate; ECG, electrocar- sidered an important physiological adaptive response to conditions in which oxygen transport is impaired, e.g., anemia (1) and myocardial failure (2). Initially, the right-shift found at high altitude (hypoxic hypoxia) was also thought to be an advantageous adaptation (3), but Hebbel et al. (4) have shown convincingly that this is not the case. In fact, the opposite, a left-shifted curve seems to be of advantage with hypoxia. With normoxic conditions, however, a left-shifted curve should theoretically be a disadvantage. The experimental evidence for this, however, is conflicting. Some authors have found a detrimental effect of a leftshifted ODC (5-7), while others have found it to be of either no or only a slight disadvantage (8-12). In a recent study (13), we measured tissue oxygen pressure in rats with increased hemoglobin oxygen affinity without finding any untoward effects. In the present study, those observations were extended to man. We used nature's own experimental model by studying two subjects with a hemoglobinopathy associated with increased hemoglobin affinity. In addition to measurements of muscle-surface oxygen pressure fields at rest, we also determined the femoral venous ( $f v$ ) oxygen pressure and saturation, leg blood flow and exchange of lactate, and some energy substrates during exercise. This was of interest, since the subjects complained of muscle fatigue during heavy physical exercise.

\section{METHODS}

Subjects. The subjects were two brothers from Finland: Subject l, age $30 \mathrm{yr}$, weight $84 \mathrm{~kg}$, height $170 \mathrm{~cm}$; subject 2 , age $31 \mathrm{yr}$, weight $71 \mathrm{~kg}$, height $166 \mathrm{~cm}$. They were both heterozygous carriers of an abnormal hemoglobin with high oxygen affinity (whole blood pressure at $50 \%$ saturation $\left[\mathrm{P}_{50}\right]$ $=13.5 \mathrm{mmHg}[1.8 \mathrm{kPa}$ ], Hill's $n=1.7$, Bohr factor $=-0.44)$. The variant hemoglobin $(\mathrm{Hb})$, which can be separated from $\mathrm{HbA}$ by thin-layer isoelectric focusing, constitutes $\sim 50 \%$ of

diogram; $\mathrm{f} v$, femoral venous; $\mathrm{Hb}$, hemoglobin; ODC, oxygen dissociation curve; $P_{.50}$, pressure at $50 \%$ saturation; $R Q$, respiratory quotient; $\dot{\mathrm{VO}}_{2}$, oxygen consumption. 
the total $\mathrm{Hb}$ of the subjects. ${ }^{2}$ The amino acid sequence has not yet been analyzed. The abnormal hemoglobin was detected when subject 1 was referred to us because of a headache. Polycythemia with a $\mathrm{Hb}$ value of $200 \mathrm{~g} / \mathrm{liter}$ was found. The headache was subsequently shown to be due to lead poisoning. When his working milieu was improved, his headache disappeared and his blood-lead values normalized. The present investigation was done when he had been free from these symptoms for 9 mo. At the time of the investigation, he was as subjectively healthy as subject 2 . Another four of eight siblings and one of two children of subject 1 have the same hemoglobinopathy. The project was approved by the local ethical committee and informed consent was obtained from the subjects.

Procedures. The investigation was performed over $2 \mathrm{~d}$. On day 1 , both subjects performed an ordinary bicycle exercise test with a diagnostic 6 lead electrocardiogram (ECG) to estimate their maximal oxygen capacity, $\left(\dot{\mathrm{V}} \mathrm{O}_{2}\right)_{\max }$, according to Åstrand and Ryhming (14). On day 2, blood flow, oxygen uptake, and turnover of energy substrates in leg muscle were determined at rest and during bicycle exercise. In subject 1 , measurement of muscle surface oxygen pressure fields was also performed on day 1 .

The day-2 study was performed in the morning in the postabsorptive state. Catheters were inserted percutaneously into the right femoral artery and both femoral veins. The tips of the catheters were placed just proximal to the inguinal ligament. To determine leg blood flow, indocyanine green dye (CARDIO-GREEN, Hynson, Westcott \& Dunning, Baltimore, MD) was infused through the femoral arterial catheter for $\sim 2-3 \mathrm{~min}$ and analyzed in $\mathrm{fv}$ blood from both sides as described by Jorfeldt and Wahren (15). Arterial (a) and $\mathrm{f} v$ samples were taken for analyses of oxygen saturation, blood gases, $\mathrm{pH}$, and various metabolites. Leg exchange of oxygen and the various metabolites was calculated from the a-fv differences and leg blood flow.

The subjects were studied at rest in the supine position and during exercise performed on a bicycle ergometer in the sitting position. Subject 1 was studied at rest and at three different work loads $(90,150$, and $200 \mathrm{~W})$, corresponding to $0.4,0.6$, and $0.8 \times\left(\dot{\mathrm{V}}_{2}\right)_{\max }$, respectively, while subject 2 was studied at rest and at 90 and $120 \mathrm{~W}$, corresponding to 0.3 and $0.5 \times\left(\dot{\mathrm{V}}_{2}\right)_{\max }$, respectively. The work periods lasted 13-17 min with 20 -min rests in the supine position in between periods. Measurements were started after $9 \mathrm{~min}$ at each work period.

A single lead ECG was recorded continuously during exercise and heart rate was measured every 5 th min. Oxygen uptake was determined by collecting expired gas in Douglas bags. Volumes were measured with a dry gas meter and expired gas fractions were analyzed with a mass spectrometer.

In subject 1 , muscle specimens from the vastus lateralis muscle were obtained at rest and within a few seconds after termination of each of the test loads, while the subject was still sitting on the ergometer (16). For biochemical analyses, the needle with its muscle sample was immediately frozen in liquid nitrogen and the sample then stored at $-80^{\circ} \mathrm{C}$ or less until analyzed. At rest, one biopsy for fiber typing was obtained with the same technique. This biopsy was mounted in embedding medium and frozen in liquid nitrogen. No muscle biopsy was taken from subject 2 .

$\mathrm{Hb}$ concentration was measured with the cyanmethemo-

${ }^{2}$ Jeppson, J.-O. 1982. Personal communication. globin technique and the hematocrit with a microcapillary hematocrit centrifuge. The partial pressures in blood for oxygen and carbon dioxide, $\mathrm{pH}$, and base excess were determined by means of a Radiometer ABL 2 blood gas apparatus (Radiometer Co., Copenhagen, Denmark). The validity of the $\mathrm{PO}_{2}$ determinations was checked by multiple point calibrations over the whole range of $\mathrm{PO}_{2}$ appearing in this study.

The oxygen affinity of the blood was determined by measurement of oxygen pressures and oxygen saturation of blood samples after tonometry with gases with varying $\mathrm{CO}_{2}$ and $\mathrm{O}_{2}$ pressures. The oxygen $\mathrm{P}_{50}$ was obtained by linear interpolation in a Hill plot and the Bohr factor by linear interpolation in a $\log \mathrm{PO}_{2} / \mathrm{pH}$ diagram. The blood of the two subjects had the same extinction curve as normal hemoglobin, so that an ordinary OSM2 Hemoximeter (Radiometer Co.) could be used for the saturation determinations. Oxygen content was calculated on the assumption that $1 \mathrm{~kg} \mathrm{Hb}$ binds $59.8 \mathrm{mmol}$ oxygen $(1,340 \mathrm{ml})$ and that the amount of oxygen dissolved in whole blood is $10 \mu \mathrm{mol} /$ (liter $\times \mathrm{kPa}$ ).

Glucose, lactate, pyruvate, glycerol, and alanine were analyzed in whole blood by enzymatic fluorimetric methods described elsewhere $(17,18)$. Similar procedures were used for the determination of muscle concentrations of glycogen, ATP, creatine phosphate (CP), and lactate $(19,20)$. Before analysis, the specimens were freeze-dried and dissected under a microscope to remove connective tissue and fat. Substrate content figures presented refer to dry weight.

For the histochemical classification of muscle fiber composition, $10-\mu \mathrm{m}$ serial transverse sections were cut with a microtome at $-20^{\circ} \mathrm{C}$ and stained for myofibrillar ATPase with a slight modification of the method of Brooke and Kaiser (21).

Measurements of muscle surface oxygen pressure fields were performed with the MDO (Mehrdraht Dortmund Oberfläche) oxygen electrode $(22,23)$. Under surgically aseptic conditions and under local anesthesia $(10 \mathrm{ml} 0.25 \%$ bupivacaine), an incision was made through the skin over the left brachioradial muscle. The surface of the muscle was freed with the utmost care. The disinfected MDO oxygen electrode was then placed on the muscle surface in a special electrode holder. (For a full description of methodology and technical equipment, see Lund [24]). To obtain sufficient observations for a statistical evaluation and to enable construction of the tissue oxygen pressure field histograms (25), the electrode was moved slightly every $30 \mathrm{~s}$ a total of 15 times. Just before moving the electrode, eight oxygen pressure values were collected and fed into a PDP 11/03 computer (Digital Equipment Corp., Maynard, MA). Each histogram thus contained 120 measured points.

Histograms were obtained when the subject inhaled room air, $70 \%$ oxygen, room air again, and finally $14 \%$ oxygen through a mouthpiece. Simultaneously, arterial samples for blood gas analysis were taken from a short teflon catheter inserted percutaneously into the right brachial artery.

A normal histogram is Gaussian in shape with a mean usually between 1 and $3.5 \mathrm{kPa}$ when measured on skeletal muscle (25-27). Abnormal histograms are of two types: one looks like a downhill ski slope and usually begins at the origin. In the other type, the registered values are widely scattered. The ski-slope type indicates impaired tissue oxygenation, while the meaning of the scattered type is yet to be defined $(25,28)$.

Reference material, data presentation, and statistical methods. The results of the leg blood flow and substrate turnover study were compared with data obtained with identical procedures in six healthy male students of physical ed- 
TABLE I

Data Obtained at Rest and during Exercise on Three Different Work Loads

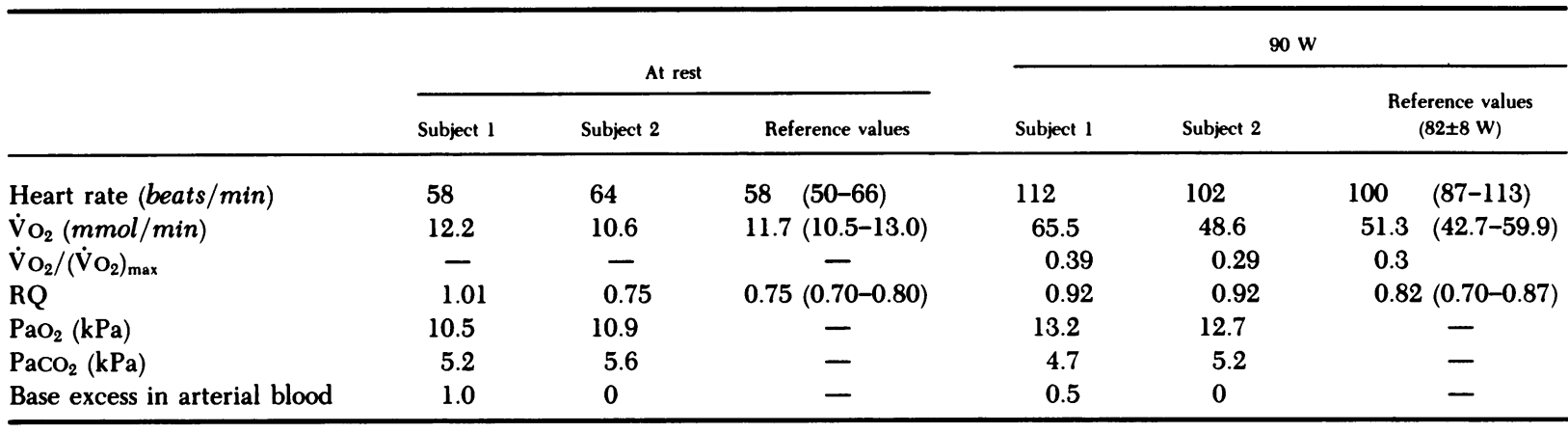

Mean values and within parentheses the $95 \%$ confidence interval for the reference material ${ }^{3}$ are given.

ucation (mean age $24 \mathrm{yr}$, range $21-35 \mathrm{yr}$ ) ${ }^{3}$ For some variables, such as leg oxygen uptake and leg blood flow, it is obvious that the changes induced by exercise correlate more closely to the work load expressed in absolute terms than to the load expressed in relative terms, whereas for others, such as arterial lactate, the opposite is true (29). For most variables, it has not been established whether absolute or relative work load is the best correlate. It is therefore necessary that the reference material is comparable not only in absolute but also in relative terms. Our two subjects had an estimated $\left(\dot{V}_{\mathrm{O}_{2}}\right)_{\max }$ of 3.4 and 3.7 liters $/ \mathrm{min}$, respectively, and the corresponding figure for the reference material was 3.8 liters/ min (mean; the range was 3.3-4.3 liters/min). The physical fitness of our subjects was thus similar to that of the reference material. Subject 1 was studied at work loads of 90,150 , and $200 \mathrm{~W}$ and subject 2 at 90 and $120 \mathrm{~W}$. The corresponding figures for the reference material were 82 (range 70-90 W), 168 (range 140-190 W), and $247 \mathrm{~W}$ (range, 210-280 W). The estimated relative work loads for subject 1 were 39,58 , and $80 \%$ and for subject 2,29 and $48 \%$. For the reference material, the corresponding figures were 30,60 , and $90 \%$. Thus, both in absolute and relative terms, the workloads studied in our subjects were within the range of the workloads studied in the reference material.

A muscle-surface oxygen pressure histogram is mathematically described by its mean, standard deviation, skewness, kurtosis, and distribution type. A statistical method for testing one histogram against another must thus test not only mean values but also the other variables. For this, the twosample Kolmogorov-Smirnov test (30) was used.

\section{RESULTS}

$\mathrm{Hb}$ concentration and hematocrit. The $\mathrm{Hb}$ concentrations for the two subjects were 198 and $182 \mathrm{~g} /$ liter, respectively, and the corresponding hematocrits were 0.55 and 0.54 .

Physical work performance, gas exchange, and mechanical efficiency (Table I). The subjects had normal estimated age corrected $\left(\dot{V}_{\mathrm{O}_{2}}\right)_{\max }$. Subject 1 had

\footnotetext{
${ }^{3}$ Juhlin-Dannfelt, A. 1982. Personal communication.
}

3.4 liters/min, corresponding to $43 \mathrm{ml}(\mathrm{min} \cdot \mathrm{kg})$, and subject 2 had 3.7 liters $/ \mathrm{min}$ and $52 \mathrm{ml} /(\mathrm{min} \cdot \mathrm{kg})$. Subject 1 reached a heart rate of $154 / \mathrm{min}$ and the exercise test was interrupted because of a moderate leg fatigue. Otherwise, he had no symptoms. Subject 2 experienced a severe leg fatigue already at the second work load of $120 \mathrm{~W}$, which was therefore his maximum. He reached a heart rate of $136 / \mathrm{min}$. The ECG was normal both at rest and during exercise in both individuals. In subject 1 , the respiratory exchange ratio $(R Q)$ was high at rest and during the lowest work load, but was within normal limits at the two higher loads. Subject 2 had a normal RQ at rest, a slightly increased value on load 1 , and a low value on the second load. The total body mechanical efficiency was normal at the different work loads.

Leg blood flow and oxygen extraction (Fig. 1). Leg blood flow was normal at rest and during exercise, as compared with the reference material. The fv oxygen pressure was low both at rest and during exercise. In spite of this, owing to the left-shifted ODC, the $\mathrm{fv}$ oxygen saturation was increased during work. The afv oxygen content difference was essentially normal at rest and at $90 \mathrm{~W}$, but was slightly lower than normal at the higher work loads.

Leg uptake and release of substrates (Fig. 2). Arterial glucose concentration was low both at rest and during exercise. The leg glucose uptake, however, was normal. The arterial lactate levels were normal at rest and during the lowest level of exercise and at the lower $95 \%$ confidence limits of the reference material at the moderate and high work loads. The lactate release was normal in both subjects both at rest and during exercise, with the exception of a low release at the highest workload in subject 1 . The arterial concentrations and the leg turnover of pyruvate, glycerol, and alanine showed only occasional minor deviations from the normal range. 


\begin{tabular}{|c|c|c|c|c|}
\hline $\begin{array}{l}\text { Subject } 1 \\
(150 \mathrm{~W})\end{array}$ & $\begin{array}{c}\text { Subject } 2 \\
(120 \mathrm{~W})\end{array}$ & $\begin{array}{c}\text { Reference values } \\
(168 \pm 17 \mathrm{~W})\end{array}$ & Subject 1 & $\begin{array}{c}\text { Reference values } \\
(247 \pm 24 \mathrm{~W})\end{array}$ \\
\hline 150 & 138 & $(123-149)$ & 176 & $(165-207)$ \\
\hline 99.8 & 78.8 & $98.0 \quad(84.1-111.9)$ & 128.5 & $151.4(134.1-168.8)$ \\
\hline 0.58 & 0.48 & 0.6 & 0.80 & 0.9 \\
\hline 4.5 & 5.6 & - & 4.5 & - \\
\hline-4.0 & -1.0 & - & -7.0 & - \\
\hline
\end{tabular}

Muscle biopsy analyses. Muscle metabolites were analyzed in subject 1 (Table II). The concentration of ATP was normal both at rest and during exercise. The $\mathrm{CP}$ concentration decreased to a subnormal value at the termination of the highest work load but was otherwise normal. Furthermore, the glycogen content was
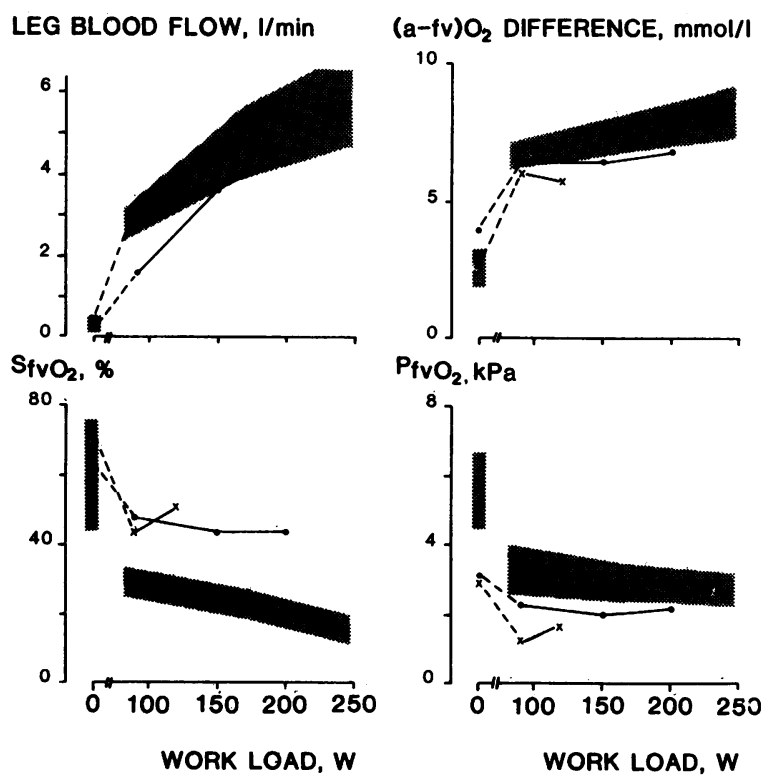

Figure 1 Leg blood flow, a-fv oxygen difference, fv oxygen saturation, and $f v$-oxygen pressure in the two subjects at rest and during exercise. The work loads were as follows: in subject $1(0) 90,150$, and $200 \mathrm{~W}$, corresponding to 39,58 , and $80 \%$ respectively, of estimated $\left(\dot{V}_{2}\right)_{\text {max }}$; and in subject 2 (X) 90 and $120 \mathrm{~W}$, corresponding to 29 and $48 \%$ of estimated $\left(\mathrm{V}_{2}\right)_{\max }$. The calculated $95 \%$ confidence intervals of the means for a reference group of healthy male students of physical education studied with identical procedures under similar absolute and relative exercise conditions (see Table I) are indicated by the shadowed areas. normal at rest and at 90 - and $150-\mathrm{W}$ exercise, but at the termination of the highest work load it decreased to a level less than half that found in normal subjects after a corresponding type of exercise. The lactate concentration was never increased.

Muscle histochemistry was studied in subject 1 . About 200 fibers were counted. $45 \%$ of them were classified as type I, $12 \%$ as type IIa, and $43 \%$ as type IIb. No type IIc fibers were found. The type I and type II fibers tended to be grouped in clusters.

Muscle-surface oxygen pressure fields (subject 1). The histograms are shown in Fig. 3. The distribution types of the histograms obtained during the breathing of room air (measurements Nos. 1 and 3) lacked the "tail" of high oxygen pressures, but were not statistically different from the normal. The histogram registered during the breathing of $70 \%$ (measurement No. 2 ) and $14 \%$ oxygen (measurement No. 4) were both abnormal and of the scattered type. Statistical comparison of the distribution types revealed that these histograms were significantly different from those obtained during air breathing $(P<0.05)$.

\section{DISCUSSION}

There is reason to believe that subjects with an abnormal $\mathrm{Hb}$ that has an increased oxygen affinity suffer an impaired oxygen delivery to the periphery. Owing to the leftward shift of the ODC, oxygen is released either at a lower partial pressure or to a lesser degree per unit of $\mathbf{H b}$. In a compromised situation, both mechanisms may be involved.

The present data on venous oxygen saturation and pressure support the compromise alternative. Thus, at rest in the supine position and during light, moderate, and heavy bicycle exercise, the fv oxygen tension was below the $95 \%$ confidence limit of the mean of a ref- 
ARTERIAL, mmol/I

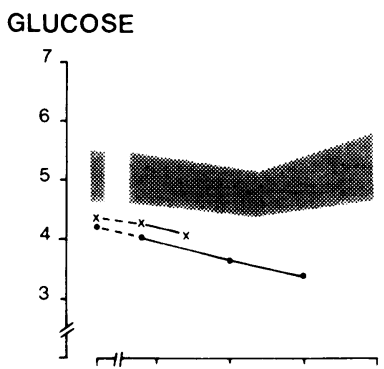

LACTATE

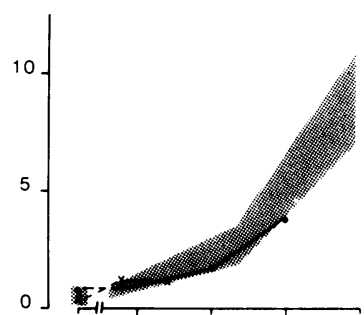

PYRUVATE
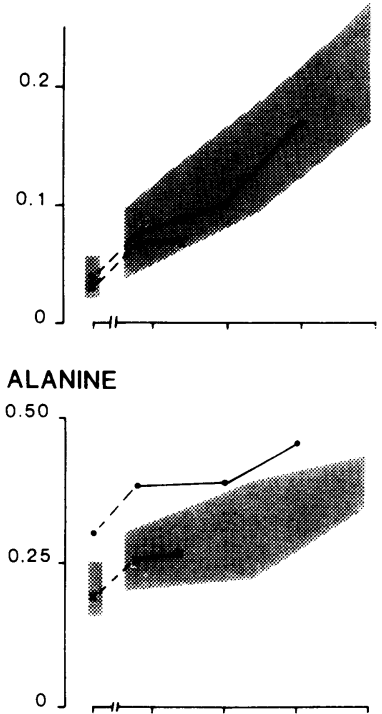

GLYCEROL
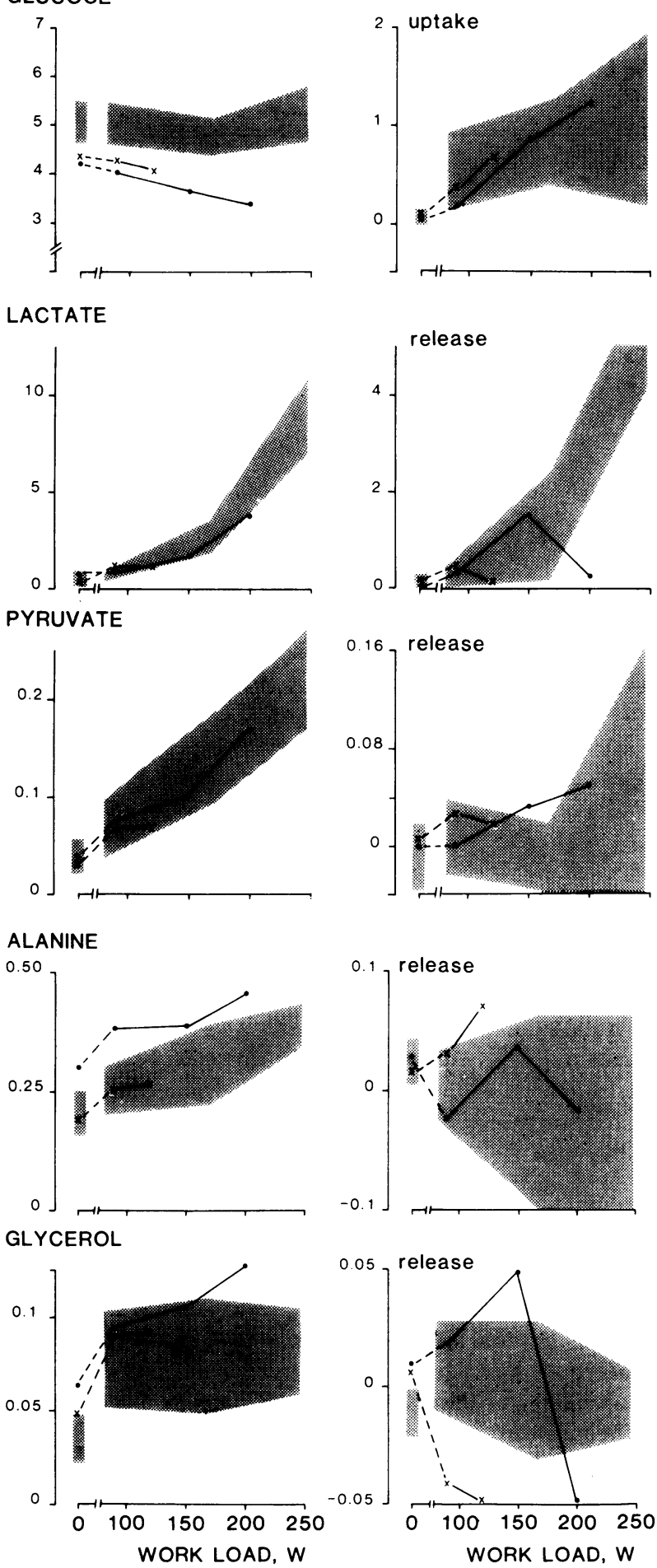

Figure 2 Arterial concentration and leg exchange (uptake or release) of some blood-borne energy metabolites. Symbols are the same as in Fig. 1 erence group of healthy subjects studied under the same conditions. Furthermore, owing to the displacement of the ODC, oxygen saturation during exercise was above the corresponding confidence limit.

The influence of the impaired oxygen release on oxygen transport with a relatively large amount of oxygen still bound to the venous effluent from the tissues can, at least partly, be compensated for by a high $\mathrm{Hb}$ concentration. Like all other subjects with a leftshifted ODC due to an abnormal hemoglobin (31), our subjects had an increased $\mathrm{Hb}$ concentration. This erythrocytosis is believed to be induced by a low oxygen pressure in the erythropoetin-producing tissue (32). Obviously, hypoxia occurs in that tissue, but that does not necessarily mean that hypoxla occurs in other tissues as well. The normal exercise ECG response in our two subjects indicates that at least the myocardial oxygenation was normal.

Some authors claim that an increased $\mathrm{Hb}$ oxygen affinity has a detrimental effect on tissue oxygenation $(5-7)$, whereas others have found that an increased $\mathrm{Hb}$ oxygen affinity is of no disadvantage or only a slight disadvantage in this respect (8-13). One explanation for the varying opinions may be that different organs have been studied. Another explanation may be that other available compensatory mechanisms besides erythrocytosis, e.g., an increase in blood flow, may have masked possible adverse effects in some experiments. Results from studies in which blood flow was kept constant speak in favor of this hypothesis $(5,7)$ for liver and brain, but not for muscle (33). Clearly, the papers of Bakker et al. (5) and of Woodson et al. (7) show that under special conditions a leftward shift of the ODC requires some compensation or the $\dot{\mathrm{V}}_{\mathrm{O}_{2}}$ will fall. However, unwanted changes, not directly related to the shift of the ODC, may be induced by the experimental setup per se. For instance, Yhap et al. (34) have reported a decreased oxygen release in an isolated hind-limb preparation during perfusion with acid citrate dextrose (ACD)-stored blood compared with fresh ACD blood and ascribed the results to the leftward shift of the ODC. Ross and Hlastala (33) reproduced these experimental results with ACD blood, but when the ODC was shifted to the left by incubation of cells in sodium metabisulfite or sodium cyanate no such effect was seen. Apparently factors other than the shift in oxygen affinity influenced the results. Here we extended these experiments to human skeletal muscle, studying two individuals with a hemoglobinopathy with a left-shifted ODC, thus avoiding experimental interference with the blood.

As was pointed out above, the $f v$ oxygen pressure was lower than normal both at rest and during exercise in our subjects, whereas the oxygen saturation was higher than in normals during exercise. The a-fv ox- 
TABLE II

Muscle Biopsy Analyses in Subject 1

\begin{tabular}{lcccc} 
& & \multicolumn{4}{c}{ During exercise } \\
\cline { 3 - 5 } & \multicolumn{1}{c}{ At rest } & \multicolumn{3}{c}{$200 \mathrm{~W}$} \\
\hline & & \multicolumn{2}{c}{$\mathrm{mmol} / \mathrm{kg}$} \\
Glycogen & $293(281,212-350)$ & $240(283,226-340)$ & $242(235,173-297)$ & $66(158,96-219)$ \\
ATP & $23(21,16-26)$ & $25(28,23-33)$ & $26(25,20-30)$ & $20(22,14-30)$ \\
CP & $143(98,67-129)$ & $97(90,62-118)$ & $88(79,64-94)$ & $26(50,32-68)$ \\
Lactate & $4(7,0-15)$ & $7(4,1-7)$ & $8(20,7-33)$ & $24(50,42-58)$ \\
\hline
\end{tabular}

Content of glycogen, ATP, CP, and lactate in muscle tissue (in millimoles glucose units per kilogram dry muscle) at rest and during exercise at different work loads. Numbers in parentheses are given mean values and the $95 \%$ confidence interval of the reference material.

ygen content difference of our subjects was normal or close to normal at rest and during the $90-\mathrm{W}$ exercise. At the heavier work loads, however, the a-fv oxygen content difference tended to be lower than in normals, since our subjects failed to increase their oxygen extraction. This indicates that the left-shifted ODC in our patients may have impaired the oxygen delivery to exercising skeletal muscles. Since patients with hemoglobinopathies are heterozygotes, their erythrocytes contain about equal parts of the normal and the abnormal hemoglobins. This was also true for our two subjects. It has been speculated (35) that only the nor$\mathrm{mal} \mathrm{Hb}$ contributes to the oxygen transport, but experimental data have until now been lacking. From our data, it can be calculated that even with maximal oxygen extraction from the normal $\mathrm{Hb}$ some oxygen must be delivered by the abnormal $\mathrm{Hb}$. Calculated from a venous oxygen saturation of the normal hemoglobin of $15 \%$, the abnormal Hb contributes $\sim 25 \%$ of the oxygen transport at relatively heavy exercise.

In these calculations, it was assumed that our subjects had equal parts of normal and abnormal $\mathrm{Hb}$ and that the sum of these was $190 \mathrm{~g} /$ liter. It was also assumed that the normal and abnormal $\mathrm{Hb}$ each had an oxygen binding capacity of $59.8 \mathrm{ml} \mathrm{O}_{2} / \mathrm{kg} \mathrm{Hb}$. According to these values, the maximal oxygen capacity of our subjects' blood was $0.190 \times 59.8=11.4 \mathrm{mmol}$ $\mathrm{O}_{2} /$ liter blood, i.e., the normal and abnormal $\mathrm{Hb}$ can carry maximally $5.7 \mathrm{mmol} \mathrm{O}_{2} /$ liter blood each, the small amount of physically dissolved oxygen being disregarded. The measured a-fv oxygen difference was $6.5 \mathrm{mmol} \mathrm{O}_{2} /$ liter, so that, even if the extraction of oxygen from the normal hemoglobin was total, some oxygen had to be delivered from the abnormal hemoglobin. As the venous $\mathrm{Po}_{2}$ was $2 \mathrm{kPa}$, the venous oxygen saturation of the normal hemoglobin more likely was of the order of $15 \%$, implying that $\sim 25 \%$ of the oxygen was delivered via the abnormal hemoglobin.
All the previously discussed data thus seem to favor the hypothesis that a left-shifted ODC causes subnormal oxygen tensions even in skeletal muscle. This would be detrimental to exercising muscle, with its considerable demand for regeneration of ATP and thus for mitochondrial oxidation. Even a very low oxygen tension, however, is sufficient for mitochondrial oxidation. Even if a diffusion gradient from the erythrocytes to the mitochondria is allowed for, the capillary oxygen tension critical for the mitochondria in the muscle is at a level at which the normal and abnormal ODC approach each other. It is thus not necessarily true that a leftward shift of the ODC is detrimental for oxygen delivery to the working skeletal muscle and the heart. In agreement with this notion is the lack of repolarization (ST-T) changes in the ECG and the low lactate production during the stress test in our two subjects.

With a deficiency or absence of oxygen, ATP can, to some extent, be resynthesized in the tissue by glycogenolysis with the formation of lactate. Such a mechanism has been suggested as an explanation for the supranormal production of lactate from working muscle during exercise at high altitude (29) and in patients with an impaired arterial inflow to the exercising muscle (36). In addition, the lactate release normally seen during exercise has been considered to be due to a relative hypoxia in muscle. In our patients, the arterial lactate concentration, the lactate release from the leg, and the muscle lactate concentration were all normal or subnormal at rest and during exercise. These findings indicate that in spite of the abnormal hemoglobin, muscle oxygen pressure was satisfactory for adequate intramitochondrial pyruvate oxidation. These results speak against the hypothesis than an exercise-induced tissue hypoxia causes the lactate release seen during exercise in normal subjects, since that lactate release occurs even at venous oxygen pressures that are clearly quite higher than in the present two subjects. The im- 


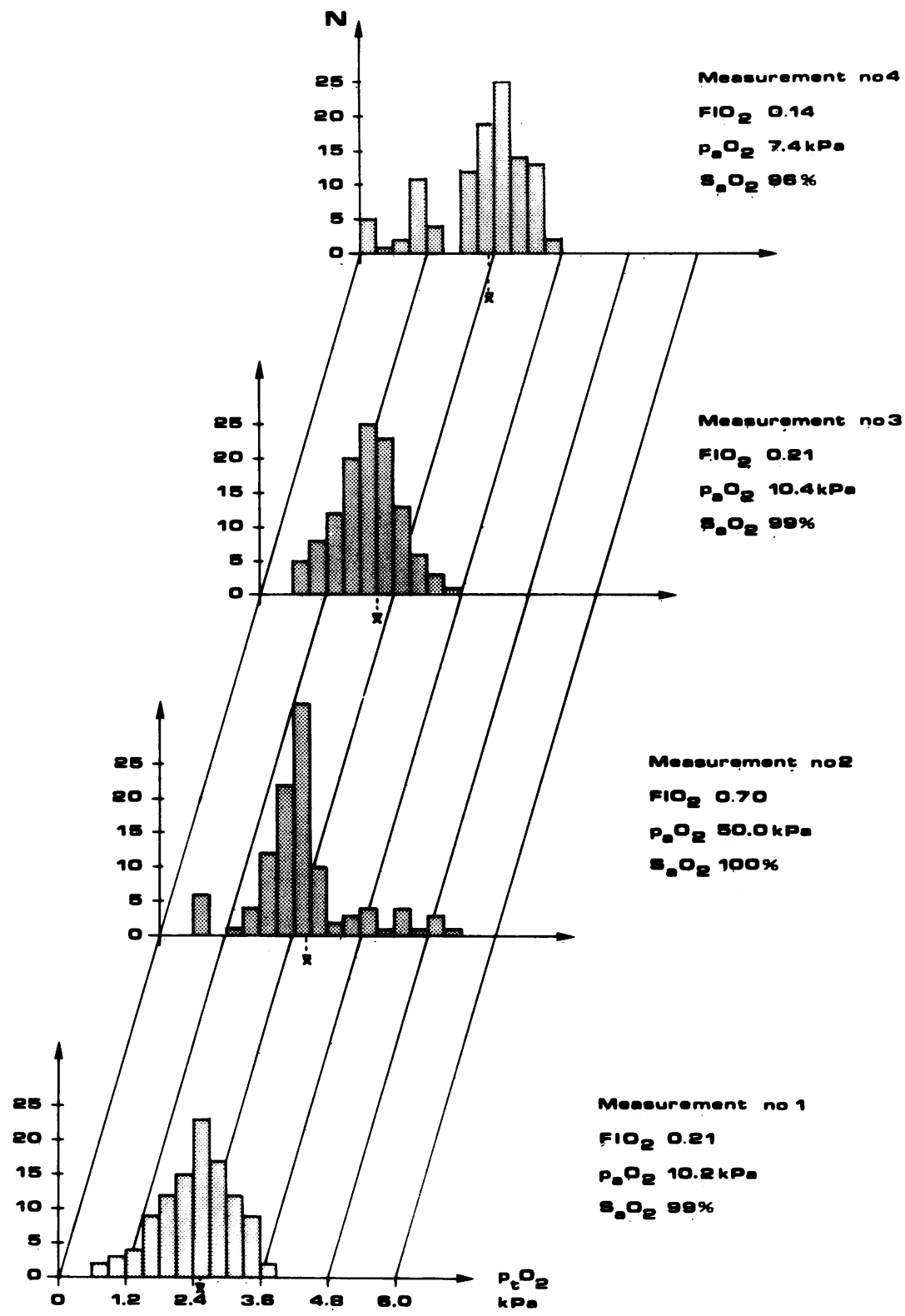

FIGURE 3 Muscle-surface oxygen field histograms from subject 1 inhaling room air (lower

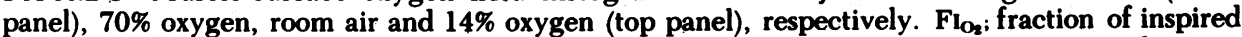
oxygen; $\mathrm{p}_{2} \mathrm{O}_{2}$, arterial oxygen pressure; $\mathrm{S}_{2} \mathrm{O}_{2}$; arterial oxygen saturation; $\mathrm{P}_{1} \mathrm{O}_{2}$, muscle tissue oxygen tension, $\bar{x}$, mean.

portance of tissue hypoxia in lactate production during exercise in man has also been questioned by others $(37,38)$.

The spatial and temporal distribution of oxygen pressure in the super stratum of skeletal muscle has been extensively studied in man and animals $(25,27$, 28). The results are often displayed as oxygen pressure frequency histograms, which in normal subjects are bell shaped, but generally slighty assymetrical with an overrepresentation of relatively high oxygen tensions (27). Typical figures for the 10th and 90th percentiles are 0.4 and $7.2 \mathrm{kPa}$, respectively, and for the median $2.5 \mathrm{kPa}$. This considerable range of oxygen pressures on the muscle surface is attributed to temporal and spatial variations in the metabolism/perfusion relationship. 
With the latter relationship unchanged, the presence of a $\mathrm{Hb}$ with an increased oxygen affinity, with or without elevated $\mathrm{Hb}$ concentration, would theoretically reduce the median of oxygen pressures and the scattering, including the tail of high oxygen pressures. We were able to study the skeletal muscle surface oxygen pressure fields in subject 1 . Breathing room air, the subject showed frequency histograms that were bell shaped, as in a normal subject, but their scattering was smaller and they did not show the tail at the highpressure end. These findings, although statistically not significant, are in agreement with the theoretical considerations. Their biological significance cannot be established, since the data have been obtained from only one subject. However, two histograms obtained on different occasions were concordant.

The findings discussed above do not indicate that muscle hypoxia existed at rest or during exercise in our two subjects. However, both of them, as in the subject with $\mathrm{Hb}$ Osler $\left(\mathrm{P}_{50}=11-12 \mathrm{mmHg}\right)$ described by Butler et al. (39), experienced marked leg fatigue at the end of the highest work load. In subject 2 , this tiredness was actually quite severe. In this situation, the muscle ATP was essentially unchanged, but the CP concentration was considerably reduced. The latter was below the $95 \%$ confidence interval for the reference material and was reduced to a level seen at maximal work loads in normal subjects. This depletion occurred simultaneously with a pronounced decrease in glycogen during the last exercise period. It thus seems that despite the lack of obvious signs of muscle hypoxia, energy generation was insufficient. Furthermore, the data show that mitochondria were capable of assimilating pyruvate from the glycogenolysis. These findings might indicate that the mitochondria were not sufficiently fed with substrate from fat oxidation. However, we have no data to support this hypothesis.

In conclusion, we found no evidence of hypoxia in skeletal or heart muscle, not even at heavy exercise in two subjects with a pronounced left-shifted ODC. The subjects complained of muscle fatigue and the CP in muscle was low, indicating poor energy generation.

\section{ACKNOWLEDGMENTS}

This work was supported by the County Council of Östergötland and the Swedish Medical Research Council (grants 04139 and 05956) and by the M. Bergvall's Research Foundation.

\section{REFERENCES}

1. Torrance, J., P. Jacobs, A. Restrepo, J. Eschbach, C Lenfant, and C. A. Finch. 1970. Intraerythrocytic adaptation in anemia. N. Engl. J. Med. 283:165-169.
2. Woodson, R. D., J. D. Torrance, S. D. Shappell, and C. Lenfant. 1970. The effect of cardiac disease on hemoglobin-oxygen binding. J. Clin. Invest. 49:1349-1356.

3. Lenfant, C., J. D. Torrance, and C. Reynafarje. 1971. Shift of the $\mathrm{O}_{2}-\mathrm{Hb}$ dissociation curve at altitude: mechanism and effect. J. Appl. Physiol. 30:625-631.

4. Hebbel, R. P., J. W. Eaton, R. S. Kronenberg, E. D. Zanjani, L. G. Moore, and E. M. Berger. 1978. Human Llamas. Adaptation to altitude in subjects with high hemoglobin oxygen affinity. J. Clin. Invest. 62:593-600.

5. Bakker, J. C., G. C. Gortmaker, and F. G. J. Offerijns. 1976. The influence of the position of the oxygen dissociation curve on oxygen-dependent functions of the isolated perfused rat liver. II. Studies at different levels of hypoxia induced by decrease of blood flow rate. Pfluegers Arch. Eur. J. Physiol. 366:45-52.

6. Malmberg, P. O., M. P. Hlastala, and R. D. Woodson. 1979. Effect of increased blood-oxygen affinity on oxygen transport in hemorrhagic shock. J. Appl. Physiol. 47:889-895.

7. Woodson, R. D., J. H. Fitzpatric, Jr., D. J. Costello, and D. D. Gilboe. 1982. Increased blood oxygen affinity decreases canine brain oxygen consumption. J. Lab. Clin. Med. 100:411-424.

8. Riggs. T. E., A. W. Shafer, and C. L. A. Guenter. 1973. Acute changes in oxyhemoglobin affinity. Effects on oxygen transport and utilization. J. Clin. Invest. 52:26602663.

9. Woodson, R. D., B. Wranne, and J. C. Detter. 1973. Effect of increased blood oxygen affinity on work performance of rats. J. Clin. Invest. 52:2717-2724.

10. Wranne, B., L. Nordgren, and R. D. Woodson. 1974. Increased blood oxygen affinity and physical work capacity in man. Scand. J. Clin. Lab. Invest. 33:347-352.

11. Artursson, G., and M. Westman. 1975. Survival of rats subjected to acute anemia at different levels of erythrocyte 2,3-diphosphorglycerate. Scand. J. Clin. Lab. Invest. 35:745-751.

12. Bakker, J. C., G. C. Gortmaker, A. de Vries-van Rossen, and F. G. J. Offerijns. 1977. The influence of the position of the oxygen disociation curve on oxygen-dependent functions of the isolated perfused rat liver. III. Studies at different levels of anaemic hypoxia. Pfluegers Arch. Eur. J. Physiol. 368:63-70.

13. Nylander, E., N. Lund, and B. Wranne. 1983. Effect of increased blood oxygen affinity on skeletal muscle surface oxygen pressure fields. J. Appl. Physiol. Respir. Environ. Exercise Physiol. 55:99-104.

14. Åstrand, P. O., and I. Rhyming. 1954. A calculation of aerobic capacity (physical fitness) from pulse rate during submaximal work. J. Appl. Physiol. 7:218-221.

15. Jorfeldt, L., and J. Wahren. 1971. Leg blood flow during exercise in man. Clin. Sci. (Lond.). 41:459-473.

16. Bergström, J. 1962. Muscle electrolytes in man. Scand. J. Clin. Lab. Invest. 14:(Suppl. 68)11-13.

17. Jorfeldt, L., and A. Juhlin-Dannfelt. 1978. The influence of ethanol on splanchnic and skeletal muscle metabolism in man. Metab. Clin. Exp. 27:97-106.

18. Stjernström, H., L. Jorfeldt, and L. Wiklund. 1981. Interrelationship between splanchnic and leg exchange of glucose and other blood-borne energy metabolites during abdominal surgical trauma. Clin. Physiol. 1:59-72.

19. Karlsson, J., B. Diamant, and B. Saltin. 1970. Muscle metabolites during submaximal and maximal exercise in man. Scand. J. Clin. Lab. Invest. 26:385-394.

20. Lowry, O. H., and J. V. Passonneau. 1972. A flexible 
system of enzymatic analysis. Academic Press, Inc., New York. 151-153, 189-191, 194-196.

21. Brooke, M. H., and K. K. Kaiser. 1970. Three "myosin adenosine triphosphatase" systems: the nature of their pH lability and sulfhydryl dependence. J. Histochem. Cytochem. 18:670-672.

22. Kessler, M., and D. W. Lübbers. 1966. Aufbau und Anwendungsmöglichkeiten verschiedener $\mathrm{pO}_{2}$-elektroden. Pfluegers Archiv Gesamte Physiol. Menschem Tiere. 291:R82.

23. Kessler, M., and W. Grünewald. 1969. Possibilities of measuring oxygen pressure fields in tissue by multiwire platinum electrodes. Prog. Respir. Res. 3:147-152.

24. Lund, N. 1979. Studies on skeletal muscle surface oxygen pressure fields. Ph. D. thesis. Linköping University Medical Dissertations, Sweden. No. 71.

25. Lübbers, D. W. 1977. Quantitative measurement and description of oxygen supply to the tissue. In Oxygen and Physiological Function. F. F. Jöbsis, editor. Professional Information Library, Dallas, TX. 254-276.

26. Kessler, M., J. Höper, and B. A. Krumme. 1976. Monitoring of tissue perfusion and cellular function. Anesthesiology. 45:184-197.

27. Lund, N., L. Jorfeldt and D. H. Lewis. 1980. Skeletal muscle oxygen pressure fields in healthy human volunteers. A study of the normal state and the effects of different arterial oxygen pressures. Acta Anaesthesiol. Scand. 24:272-278.

28. Lund, N., L. Jorfeldt, D. H. Lewis, and S. Ödman. 1980. Skeletal muscle oxygen pressure fields in artificially ventilated critically ill patients. Acta Anaesthesiol. Scand. 24:347-353.

29. Hermansen, L., and B. Saltin. 1966. Blood lactate concentration during exercise at acute exposure to altitude. In Excerpta Medica Monograph: Exercise at Altitude. International Symposium, Milan. 48-53.
30. Lindgren, B. W. 1965. Statistical Theory. Macmillan, Inc., New York. 300-337.

31. Jones, R. T., and T.-B. Shih. 1980. Hemoglobin variants with altered oxygen affinity. Hemoglobin. 4:243-261.

32. Adamson, J. W., and C. A. Finch. 1975. Hemoglobin function, oxygen affinity and erythropoetin. Annu. Rev. Physiol. 37:351-369.

33. Ross, B. K., and M. P. Hlastala. 1981. Increased hemoglobin oxygen affinity does not decrease skeletal muscle oxygen consumption. J. Appl. Physiol. Respir. Environ. Exercise Physiol. 51:864-870.

34. Yhap, E. O., B. W. Greighton, N. A. Popovic, and E. C Alix. 1975. Decreased oxygen uptake with stored blood in the isolated hindlimb. J. Appl. Physiol. 38:882-885.

35. Poyart, C., E. Bursaux, B. Teisseire, A. Freminet, M Duvelleroy, and J. Rosa. 1978. Hemoglobin Creteil: oxygen transport to erythrocytes. In vitro and in vivo studies in a high oxygen-affinity mutant hemoglobin. Ann. Intern. Med. 88:758-763.

36. Carlson, L. A., and B. Pernow. 1959. Oxygen utilization and lactic acid formation in the legs at rest and during exercise in normal subjects and in patients with arteriosclerosis obliterans. Acta Med. Scand. 164:39-52.

37. Thomson, J. M., J. A. Dempsey, L. W. Chosy, N. T Shahidi, and W. G. Reddan. 1974. Oxygen transport and oxyhemoglobin dissociation during prolonged muscular work. J. Appl. Physiol. 37:658-664.

38. Dempsey, J. A., J. M. Thomson, H. V. Forster, F. C. Cerny, and $\mathrm{L}$. W. Chosy. $1975 . \mathrm{HbO}_{2}$ dissociation in man during prolonged work in chronic hypoxia. J. Appl. Physiol. 38:1022-1029.

39. Butler, W. M., L. Spratlin, J. A. Kark, and E. B. Schoomaker. 1982. Hemoglobin Osler: report of a new family with exercise studies before and after phlebotomy. Am. J. Hematol. 13:293-301. 